\title{
The effectiveness of functional training on impulsiveness of females with intellectual disability
}

\author{
Sakineh Farrokhian, ${ }^{1}$ Ghorban Hemati Alamdarloo, ${ }^{1}$ Enayatollah Asadmanesh ${ }^{2}$ \\ ${ }^{1}$ Special Education Department; ${ }^{2}$ Physical Education Department, School of Education and \\ Psychology, Shiraz University, Shiraz, Iran
}

\begin{abstract}
The aim of this study was to determine the effectiveness of Functional Training (FT) on impulsiveness of female students with Intellectual Disability (ID). The research method was pretestposttest- with a control group. The statistical population consisted of all female students with ID in elementary school of Shiraz studying under the auspices of the Special Education Organization in 20182019. The participants included 30 female students with ID selected through convenience sampling and randomly assigned to the experimental $(n=14)$ and control $(n=14)$ groups. The experimental group received the functional training for 15 sessions, while the control group did not receive any intervention. The Barratt Impulsiveness Scale Version 11 (BIS-11) was used for measuring the impulsiveness. The Impulsiveness pre-test was performed for both experimental and control groups. The experimental group received the FT for
\end{abstract}

Correspondence: Ghorban Hemati Alamdarloo, Special Education Department, School of Education and Psychology, Shiraz University, Shiraz, Iran.

Tel.: +98-713-6134654 - Fax: +98-713-6286441

E-mail: ghemati@shirazu.ac.ir

Key words: Functional training, impulsiveness, female, students, intellectual disability.

Acknowledgments: We would like to thank the management and all the colleagues of Ehsan Girls' Exceptional School for their cooperation in conducting this research. Thanks to the parents and students who participated in this project.

Conflict of interest: the authors declare no conflict of interest.

Contributions: The authors contributed equally.

Ethics approval and consent to participate: Consent and approval have been obtained.

Availability of data and materials: All data are available in the main text.

Received for publication: 18 May 2020.

Accepted for publication: 17 October 2020.

This work is licensed under a Creative Commons AttributionNonCommercial 4.0 International License (CC BY-NC 4.0).

${ }^{\circ}$ Copyright: the Author(s), 2020

Licensee PAGEPress, Italy

Health Psychology Research 2020; 8:9116

doi:10.4081/hpr.2020.9116
15 sessions, while the control group did not receive any intervention. At the end of the intervention, post-test was performed for both groups. Mann-Whitney $U$ test was used to analyze the data. The results showed that the mean scores of impulsivities and its subscales (motor impulsiveness, attentional impulsiveness and nonplanning impulsiveness) in the experimental group were significantly reduced. The results showed that FT had a significant effect on impulsiveness of female students with ID $(p<0.001)$. Therefore, it is recommended to design and implement a FT program to improve impulsiveness in people with ID.

\section{Introduction}

Impulsiveness means low-thinking behaviors (Swann \& Hollander, 2002). In fact, impulsive behaviors involve a wide range of actions that are performed immaturely, quickly, and without thinking and people have no idea or plan to do these behaviors (Lee, Chong, \& Coccaro, 2011). Impulsiveness has significant negative consequences (Swann \& Hollander, 2002). In fact, impulsive people behave according to their immediate and instantaneous feelings, without considering the specific rules or considerations of situations (Diemen, Szobot, Kessler, \& Pechansky, 2007). Impulsiveness is associated with a lack of cognitive inhibition and a slow and incomplete decision-making process (Gullo \& Dawe, 2008). Impulsiveness has a direct relationship with inability in self-control and inhibiting individual behavior and it is the cause of many academic, social and cognitive problems (Kovácsová, Lajunen \& Rošková, 2016). Impulsiveness is the main reason of many social harms, such as drug abuse, personality disorder and aggression. This disorder destroys time and capital in many countries every year (Arce \& Santisteban, 2006).

Impulsiveness in people with Intellectual Disability (ID) is higher than typically developing people, because cognitive development is associated with behavioral inhibition. Therefore, there is a relationship between impulsive behaviors and intellectual development (Burbidge et al., 2010). Seiger and O'Brien have shown that impulsive behaviors are more common in people with ID than in their typically developing peers (Seager \& O'Brien, 2003). In a study conducted by Bradley and Isaacs, 1 in 2 adolescents with ID and autism exhibited impulsive behaviors, and 1 in 7 adolescents with ID exhibited these behaviors (Bradley \& Isaacs, 2006). As can be seen, on the one hand, impulsiveness has many negative consequences (Swann \& Hollander, 2002; Diemen, Szobot, Kessler, \& Pechansky, 2007; Gullo \& Dawe, 2008; Kovácsová, Lajunen \& Rošková, 2016; Arce \& Santisteban, 2006) On the other hand, the prevalence of impulsive behavior is higher in people with ID than in their typically developing peers (Burbidge et al, 2010; Seager \& O'Brien, 2003; Bradley \& Isaacs, 2006). Therefore, any attempt to control and treat impulsiveness in 
children with ID is valuable. In this regard, exercise and physical activity have been recognized as an effective intervention in the prevention, reduction and treatment of psychological problems (Wipfli, Rethorst \& Landers, 2008). In this regard, Weinberg and Gould state that exercise not only has a positive effect on cognitive stability, self-control and intellectual function, but also reduces anger, anxiety, hostility and stress (Weinberg \& Gould, 2003). The findings in line above, in an experimental study in the state of Pennsylvania in the United States, a number of girls and boys with aggression were treated with exercise. These people were with ID, were highly incompatible with others. After a three-month period of exercise, many changes were reported by those around them (parents, teachers, and themselves). As most people around them believed, their problems were significantly solved. The researchers concluded that exercise as an activity can control abnormal human behavior (Crocker et al., 2006). Functional Training (FT) is a new exercise. In this method, practice of movements including change of direction, change of level and movement pattern are presented (Santana, 2016). FT is a set of sports activities that are based on daily routine activities such as walking, climbing up stairs and going down, getting up and sitting down and move light things. FT was focused improving physical fitness such as endurance, strength, flexibility and balance (Boyle, 2016; King, Judge, Whipple, \& Wolfson, 2000). FT are a challenge to the sense of movement, control of movement, and the central nervous system. During these exercises, the nervous system learns to control the whole movement and be able to make the best plans in the movement (Santana, 2016). This type of exercise is compared to traditional exercises in which instead of practicing on separate effective factors, the emphasis is on performing multi-joint, muscle and multiple factors and many parts of the body that are associated with movement are used in it (Weiss et al., 2010).

According to researchers, the effectiveness of FT on impulsiveness of children with ID has been less studied. Most families of children with ID are economically poor. They cannot afford expensive treatments such as medical and psychological services. With this research we want to help families prevent problems. It is necessary to study the effect of FT as a simple educational method without side effects. This study presents an available method for improving psychological performance of children with ID for professionals, teachers, parents and educators. Therefore, the purpose of this study was to investigate the effectiveness of FT on impulsiveness in female students with ID. We want to answer these questions: i) Does FT intervention affect the total score of impulsiveness in female students with ID? ii) Does FT intervention affect the subscales of impulsiveness in female students with ID?

\section{Materials and Methods}

\section{Population, sample, and sampling method}

The research method was experimental with pre-test and post- test with control group. The statistical population consisted of all female students with ID in elementary school of Shiraz studying under the auspices of the Special Education Organization in 20182019. The participants included 28 female students with ID selected through convenience sampling and randomly assigned to the experimental $(n=14)$ and control $(n=14)$ groups. Both groups had pre-test of impulsiveness the intervention program. After the intervention program, both groups had post-test of impulsiveness. The sample characteristics of the experimental and control groups are presented in Table 1.

\section{Procedure for FT}

FT were implemented in 15 sessions. Each session lasted from 45 to 60 minutes. These programs were run for five weeks and three sessions per week. Each exercise was repeated 3 set and 12 to 15 times per session. The movements were performed by the instructor and the children observed and performed it. The exercises are based on FT and include: i) Squat overhead: Participants placed their hands above the head and held the ball with two hands. While the legs are open, be in squat mode and knees bent 90 degrees. Then stand with hands in the same position. ii) Russian twist with ball: Sitting on the ground, knees bent, Legs together and slightly above ground level, Put the hands in front with a ball in hand, rotate the upper back straight without lowering the legs or bending and after a second pause, turn left and continue moving. iii) Lange: While holding two balls in the palm of their hand, they put one foot ahead of the other, bend one of the knees and they try to keep the waist straight. After the eight sets are over, they change their legs and continue with the other foot. iv) Landing on one leg from box: jumps down from the box with one foot and repeats again. v) Wall push up: This modified Swedish type of swimming is the most comfortable type of swim and is very convenient to start. The examiner stands in front of the wall, Hands on the wall and bends forward and returns to the first position. vi) Kick back: Straightening and stretching the left hand and right foot, then repeat with the opposite hand and foot.

\section{Instruments}

The Barratt Impulsiveness Scale Version 11 (BIS-11) has been developed by Patton, Stanford \& Barratt (Patton, Stanford, \& Barratt, 1995). BIS-11 has 30 items and three subscales: attentional impulsiveness, motor impulsiveness, and nonplanning impulsiveness. The scoring method of the scale is based on the four-point Likert scale of "1" to "4": i) rarely/never, ii) occasionally, iii) often, and iv) almost always (Reise, Moore, Sabb, Brown, \& London, 2013). The total score ranges from 30 to 120 and higher scores indicate greater impulsivity (Patton, Stanford, \& Barratt, 1995). Wan, Zhang, Jin, \& Cheng (2016) have reported reliability of this version: the internal consistency of 30 items scale and of the three 10-item subscales were excellent (Cronbach's alphas were 0.77-0.89) and the test-retest reliability was good (intraclass correlation coefficient were 0.68-0.89). Vasconcelos, Malloy-Diniz, and Correa (2012) indicated BIS-11 has reliability and criterion-related

Table 1. Sample characteristics for experimental and control groups. Experimental group $(n=14)$ Control group $(n=14)$

\begin{tabular}{lcc} 
Mean age (years) (SD) & $11.67(1.79)$ & $10.73(1.58)$ \\
Range (years) & $9-14$ & $9-14$ \\
\hline Mean height (cm) (SD) & $134.68(15.41)$ & $124.57(17.17)$ \\
Mean weight (kg) (SD) & $42.47(13.35)$ & $37.51(10.42)$
\end{tabular}


validity across samples. The reliability and validity of the questionnaire have been confirmed by various researchers (Fossati Di Ceglie, Acquarini, \& Barratt, 2001; Someya et al., 2001; Yao et al., 2007). In addition, Stanford et al. (2009) demonstrated the internal consistency $(\mathrm{a}=0.83)$, test-retest at one month ( $\mathrm{rho}=0.83)$ for lBIS11. It should be noted that the teachers individually completed the paper and pencil version of BIS-11 at school which took about 1520 minutes.

\section{Ethical considerations}

Parents gave consent for participation of their children in this study. The parents were aware of the purpose of the study and their children had the right to leave the study at any time. They were assured that all their information would remain confidential. The ethical review board of the regional Special Education Organization approved the study.

\section{Results}

In the following, the mean and standard deviation of the impulsiveness, mean difference of pre-test and post-test, Mann-Whitney $\mathrm{U}$ test result and p-value are shown regarding for the experimental and control groups, which can be seen in Table 2. The Kolmogorov-Smirnov evaluation revealed a normal distribution of data in research variables $(\mathrm{P}>0.05)$.

The average scores of both experimental and control groups in the subscales of attentional impulsiveness, motor impulsiveness, nonplanning impulsiveness and a total score of impulsiveness in the pretest are almost equal. However, after the intervention, the mean score of the experimental group in subscales of impulsiveness and its total score has been decreased. Mann-Whitney U test was used to determine the impact of FT on impulsiveness and subscales of impulsiveness of female students with ID. The results showed that the FT intervention has a significant effect in the impulsiveness of experimental group in the post-test $(\mathrm{P}<0.001)$. In addition, The results of Mann-Whitney $U$ test showed that the FT intervention has a significant effect in the attentional impulsiveness, motor impulsiveness and nonplanning impulsiveness of experimental group in the post-test $(\mathrm{P}<0.001)$.

\section{Discussion}

The aim of the present study was to investigate the effectiveness of FT on impulsiveness and its subscales in female students with ID. The results of the study showed that FT were effective on the total scores of impulsiveness and its sub-scales (motor impulsiveness, attentional impulsiveness and nonplanning impulsiveness).

Researchers have found areas of the prefrontal cortex directly involved in aspects of impulsiveness. In a parallel way, decisionmaking processes, as well as mechanisms connected with impulsiveness, are known to take place in areas of the prefrontal cortex (Arce et al., 2006). Studies based on MRI technology have shown that some areas of the forehead (upper, front, lower) are about 10 percent smaller in people with hyperactivity and impulsiveness. Molecular genetic studies have also shown that diagnoses in hyperactivity are associated with polymorphism in some dopamine genes (Nigg, 2005). Impulsiveness usually leads to undesirable consequences and it may be important as a cross-diagnostic sign in disorders such as Attention Deficit/Hyperactivity Disorder (ADHD), drug abuse, Tourette syndrome, and antisocial behavior (Dalley, Everitt, \& Robbins, 2011). Impulsiveness affects many human cognitive behaviors, including planning, decision-making, and attention (Dougherty et al., 2013).

Explaining these findings, it can be said that FT have a positive effect on the chemical-neurological part of the brain and by increasing dopamine, it stimulates the brain. Increased sensitivity of dopaminergic receptors in response to exercise-induced dopamine secretion is likely to reduce impulsiveness (Kiluk, Weden, \& Culotta, 2009; Verret, Guay, Berthiaume, Gardiner \& Béliveau, 2012). Pharmacological studies with animal subjects also suggest that brain serotonin plays an important role in maintaining the effectiveness of delayed positive reinforcers. Serotonin depletion may cause an increase in impulsive behavior due to a change in the capacity to estimate time intervals (Arce et al., 2006). FT strengthen the atrial nervous system and can reduce impulsiveness by creating the right environment for increased selfconfidence and self-empowerment (Wigal et al., 2006). Exercising by balancing the amount of epinephrine secretion in the area of the brainstem stimulation, balances the arousal of children and reduces the level of irritability in the child (Tantillo, Kesick, Hynd, \& Dishman, 2002).

Explaining the effect of FT on motor impulsiveness, it can be said that with increasing motor persistence, motor impulsiveness decreases (Hauer et al., 2012). The effect of FT is such as stimulant drugs on dopaminergic and noradrenergic systems (Wigal et al., 2006). Weber et al. (2008) in a study examined the impact of strenuous physical activity on children with ADHD. Their research showed that strenuous physical activity in people with ADHD reduced symptoms such as restlessness and excessive activity by about 95 percent. Exercise reduces the symptoms of ADHD and controls symptoms such as impulsiveness, restlessness, anxiety, and overactivity (Kiluk, Weden, \& Culotta, 2009; Verret et al.,

Table 2. Mean and standard deviation of impulsiveness and its subscales in both control and experimental groups in the pretest and posttest and results of Mann-Whitney $U$ test.

\begin{tabular}{|c|c|c|c|c|c|c|c|c|}
\hline \multirow[t]{2}{*}{ Variable } & \multirow[t]{2}{*}{ Group } & \multicolumn{2}{|c|}{ Pretest } & \multicolumn{2}{|c|}{ Posttest } & \multirow[t]{2}{*}{ Mean difference } & \multirow[t]{2}{*}{ Mann-Whitney U } & \multirow[t]{2}{*}{ Sig. } \\
\hline & & Mean & SD & Mean & SD & & & \\
\hline \multirow{2}{*}{ Total score of impulsiveness } & Experimental & 58.21 & 7.44 & 46.93 & 4.07 & 11.28 & \multirow[t]{2}{*}{14} & \multirow[t]{2}{*}{0.00} \\
\hline & Control & 60.93 & 7.32 & 61.07 & 6.87 & -0.14 & & \\
\hline \multirow[t]{2}{*}{ Attentional impulsiveness } & Experimental & 17.42 & 3.74 & 13.43 & 2.85 & 3.99 & \multirow[t]{2}{*}{25} & \multirow[t]{2}{*}{0.001} \\
\hline & Control & 18.36 & 3.69 & 18.36 & 3.20 & 0 & & \\
\hline \multirow[t]{2}{*}{ Motor impulsiveness } & Experimental & 18.14 & 3.82 & 15.07 & 3.02 & 3.07 & \multirow[t]{2}{*}{14} & \multirow[t]{2}{*}{0.001} \\
\hline & Control & 20.64 & 3.41 & 20.57 & 3.39 & 0.07 & & \\
\hline \multirow[t]{2}{*}{ Nonplanning impulsiveness } & Experimental & 22.64 & 4.83 & 18.43 & 3.41 & 4.21 & \multirow[t]{2}{*}{18} & \multirow[t]{2}{*}{0.001} \\
\hline & Control & 21.93 & 3.41 & 22.00 & 3.76 & -0.07 & & \\
\hline
\end{tabular}


2012). Attentional impulsiveness, research has shown that regular physical activity increases the level of neurotransmitters epinephrine and norepinephrine in the brain and plays a key role in regulating the attention of impulsive children (Gapin, Labban, \& Etnier, 2011; Verret et al., 2012). Exercise reduces the potential for action in the sinus-atrial node of the heart by making physiological changes, such as regulating the cardiovascular system, especially by affecting the parasympathetic autonomic nervous system and stimulating the vagus nerve, helps calm the nerves and it reduces aggression and attention deficit (Kiluk, Weden, \& Culotta, 2009; Verret et al., 2012). There is always a positive relationship between intellectual functions such as attention and motor skills (Pan, 2008). Silva et al. Concluded in a study that strenuous physical exercise can improve the attention of children and adolescents with attention deficit disorder. Exercise may be helpful for learning in these children. These effects appear immediately and help to focus them (Silva et al., 2015).

Research by Koo et al. Has shown that participating in sports activities increases accuracy and reduces learning problems for students with ADHD (Coe, Pivarnik, Womack, Reeves, \& Malina, 2006). Ploughman considers the effect of physical exercise on cognitive parameters such as attention due to increased blood oxygenation, increased secretion of neurotransmitters such as serotonin and norepinephrine, and regulation of neurotrophins (Ploughman, 2008). One of the effective mechanisms may be neural nutrition by factors such as insulin-like growth factor and neurotrophic factor derived from the brain that due prolonged motor training causes new capillaries to form, new neurons to form, cell proliferation, and nerve formation. This neural mechanism can be physiologically justified to improve cognitive function such as attention that results from exercise (Vaynman \& Gomez-Pinilla, 2005). About nonplanning impulsiveness, it can be said that people with a high level of nonplanning impulsiveness have difficulty in foresight, planning and careful thinking. In fact, they cannot anticipate unpleasant consequences of behavior and control their behavior (Stanford et al., 2009). The ability to make advantageous choices depends greatly on the capacity to plan ahead and/or to inhibit a response (Arce et al., 2006). People with high impulsiveness are less accurate and show faster time estimates than people with low impulsiveness. This problem paves the way for impulsive behaviors such as quick and thoughtless decision making (Carroll et al., 2006). Exercise has a positive effect on executive control agents, namely planning, scheduling, working memory, inhibition, and coordination of tasks (Mahon, Stephens, \& Cole, 2008). Animal studies have shown that participating in physical activity increases cerebral blood flow in areas of motor control, balance, and areas of the hippocampus. Therefore, increasing blood flow to the brain due to physical exercise and movement may provide more fuel for neural function and thus improve cognitive function (Pereira et al., 2007). FT can be used by everyone, however, in this study, due to the limitations and physical problems of the students with ID, FT adapted for them. The present study showed that FT reduces impulsive behavior in children with ID. Therefore, parents, psychologists, educators, teachers, and people who deal with students with ID can help them by using a FT approach. With a long and intensive intervention, it is better to judge whether the experimental intervention was effective. It should be noted that the present study was conducted only on female students with ID, so the generalization of the results to other students with disabilities should be carefully considered. The lack of follow-up was also one of the limitations of the present study. Convenience sampling was used for the selection of participants of this study. Therefore, generalizability of the results to the statistical population should be made with caution. In addition, the sample size of this study was small. This can threaten generalizability of the study's findings.

\section{References}

Arce, E., \& Santisteban, C. (2006). Impulsivity: A review. Psicothema, 18(2), 213-220. https://www. redalyc.org/articulo.oa?id=72718208.

Boyle, M. (2016). New functional training for sports. Champaign, IL: Human Kinetics.

Bradley, E. A., \& Isaacs, B. J. (2006). Inattention, hyperactivity, and impulsivity in teenagers with intellectual disabilities, with and without autism. The Canadian Journal of Psychiatry, 51(9), 598-606. doi: 10.1177/0706743 70605100908.

Burbidge, C., Oliver, C., Moss, J., Arron, K., Berg, K., Hill, L., Trusler, K., Furniss, F \& Woodcock, K. (2010). The association between repetitive behaviours, impulsivity and hyperactivity in people with intellectual disability. Journal of Intellectual Disability Research, 54(12), 1078-1092. doi: 10.1111/j.1365-2788.2010.01338.x.

Carroll, A., Hemingway, F., Bower, J., Ashman, A., Houghton, S., \& Durkin, K. (2006). Impulsivity in juvenile delinquency: Differences among early-onset, late-onset, and nonoffenders. Journal of Youth and Adolescence, 35(4), 517-527. doi: 10.1007/s10964-006-9053-6.

Coe, D. P., Pivarnik, J. M., Womack, C. J., Reeves, M. J., \& Malina, R. M. (2006). Effect of physical education and activity levels on academic achievement in children. Medicine \& Science in Sports \& Exercise, 38(8), 1515-1519. doi: 10.1249/01.mss.0000227537.13175.1b.

Crocker, A. G., Mercier, C., Lachapelle, Y., Brunet, A., Morin, D., \& Roy, M. E. (2006). Prevalence and types of aggressive behavior among adults with intellectual disabilities. Journal of Intellectual Disability Research, 50(9), 652-661. doi: 10.1111/j.1365-2788.2006.00815.x.

Dalley, J. W., Everitt, B. J., \& Robbins, T. W. (2011). Impulsivity, compulsivity, and top-down cognitive control. Neuron, 69(4), 680-694. doi: 10.1016/j.neuron.2011.01.020

Diemen, L. V., Szobot, C. M., Kessler, F., \& Pechansky, F. (2007). Adaptation and construct validation of the Barratt Impulsiveness Scale (BIS 11) to Brazilian Portuguese for use in adolescents. Brazilian Journal of Psychiatry, 29(2), 153156. doi: 10.1590/S1516-44462006005000020.

Dougherty, D.M., Mathias, C.W., Dawes, M.A., Furr, R.M., Charles, N.E., Liguori, A., \& Acheson, A. (2013). Impulsivity, attention, memory, and decision-making among adolescent marijuana users. Psychopharmacology, 226(2), 307-319. doi: 10.1007/s00213-012-2908-5.

Fossati, A., Di Ceglie, A., Acquarini, E., \& Barratt, E. S. (2001). Psychometric properties of an Italian version of the Barratt Impulsiveness Scale $\square 11 \quad$ (BIS $\square 11$ ) in nonclinical subjects. Journal of clinical psychology, 57(6), 815-828. doi: 10.1002/jclp.1051.

Gapin, J. I., Labban, J. D., \& Etnier, J. L. (2011). The effects of physical activity on attention deficit hyperactivity disorder symptoms: The evidence. Preventive Medicine, 52, 70-74. doi: 10.1016/j.ypmed.2011.01.022.

Gullo, M. J., \& Dawe, S. (2008). Impulsivity and adolescent substance use: Rashly dismissed as "all-bad"? Neuroscience \& Biobehavioral Reviews, 32(8), 1507-1518. doi: 10.1016/j.neu- 
biorev.2008.06.003

Hauer, K., Schwenk, M., Zieschang, T., Essig, M., Becker, C., \& Oster, P. (2012). Physical training improves motor performance in people with dementia: a randomized controlled trial. Journal of the American Geriatrics Society, 60(1), 8-15. doi: 10.1111/j.1532-5415.2011.03778.x.

Kiluk, B. D., Weden, S., \& Culotta, V. P. (2009). Sport participation and anxiety in children with ADHD. Journal of Attention Disorders, 12(6), 499-506. doi: 10.1177/1087054708320400.

King, M. B., Judge, J. O., Whipple, R., \& Wolfson, L. (2000). Reliability and responsiveness of two physical performance measures examined in the context of a functional training intervention. Physical Therapy, 80(1), 8-16. doi: 10.1093/ptj/80.1.8.

Kovácsová, N., Lajunen, T., \& Rošková, E. (2016). Aggression on the road: Relationships between dysfunctional impulsivity, forgiveness, negative emotions, and aggressive driving. Transportation Research Part F: Traffic Psychology and Behavior, 42, 286-298. doi: 10.1016/j.trf.2016.02.010

Lee, R., Chong, B., \& Coccaro, E. (2011). Growth hormone responses to $\mathrm{GABAB}$ receptor challenge with baclofen and impulsivity in healthy control and personality disorder subjects. Psychopharmacology, 215(1), 41-48. doi: 10.1007/s00213-010-2116-0.

Mahon, A. D., Stephens, B. R., \& Cole, A. S. (2008). Exercise responses in boys with attention deficit/hyperactivity disorder: effects of stimulant medication. Journal of Attention Disorders, 12(2), 170-176. doi: 10.1177/1087054707308484.

Nigg, J. T. (2005). Neuropsychologic theory and findings in attention-deficit/hyperactivity disorder: the state of the field and salient challenges for the coming decade. Biological Psychiatry, 57(11), 1424-1435. doi: 10.1016/j.biopsych. 2004.11.011.

Pan, C. Y. (2008). Objectively measured physical activity between children with autism spectrum disorders and children without disabilities during inclusive recess settings in Taiwan. Journal of Autism and Developmental Disorders, 38(7), 1292. doi: 10.1007/s10803-007-0518-6.

Patton, J. H., Stanford, M. S., \& Barratt, E. S. (1995). Factor structure of the Barratt impulsiveness scale. Journal of Clinical Psychology, 51(6), 768-774. doi: 10.1002/10974679(199511)51:6\%3C768::AID-JCLP2270510607\% 3E3.0.CO;2-1.

Pereira, A. C., Huddleston, D. E., Brickman, A. M., Sosunov, A. A., Hen, R., McKhann, G. M., Sloan, R., Gage, F. H., Brown, T. R. y Small, S. A. (2007). An in vivo correlate of exerciseinduced neurogenesis in the adult dentate gyrus. Proceedings of the National Academy of Sciences, 104(13), 5638-5643. doi: 10.1073/pnas.0611721104.

Ploughman, M. (2008). Exercise is brain food: The effects of physical activity on cognitive function. Developmental Neurorehabilitation, 11(3), 236-240. doi: 10.1080/1751842080 1997007.

Reise, S. P., Moore, T. M., Sabb, F. W., Brown, A. K., \& London, E. D. (2013). The Barratt Impulsiveness Scale-11: Reassessment of its structure in a community sample. Psychological Assessment, 25(2), 631-642. doi: 10.1037/a0032161.

Santana, J. C. (2016). Functional Training: Exercises and programming for training and performance. Estados Unidos: Human Kinetics.

Seager, M. C., \& O'Brien, G. (2003). Attention deficit hyperactivity disorder: Review of ADHD in learning disability: The diag- nostic criteria for psychiatric disorders for use with adults with learning disabilities/mental retardation [DC $\square \mathrm{LD}$ ] criteria for diagnosis. Journal of Intellectual Disability Research, 47, 2631. doi: 10.1046/j.1365-2788.47.s1.30.x.

Silva, A. P., Prado, S. O., Scardovelli, T. A., Boschi, S. R., Campos, L. C., \& Frère, A. F. (2015). Measurement of the effect of physical exercise on the concentration of individuals with ADHD. PLoS One, 10(3), e0122119. doi: 10.1371/journal.pone.0122119.

Someya, T., Sakado, K., Seki, T., Kojima, M., Reist, C., Tang, S. W., \& Takahashi, S. (2001). The Japanese version of the Barratt Impulsiveness Scale, 11th version (BIS $\square$ 11): Its reliability and validity. Psychiatry and Clinical Neurosciences, 55(2), 111-114. doi: 10.1046/j.14401819.2001.00796.x

Stanford, M. S., Mathias, C. W., Dougherty, D. M., Lake, S. L., Anderson, N. E., \& Patton, J. H. (2009). Fifty years of the Barratt Impulsiveness Scale: An update and review. Personality and Individual Differences, 47(5), 385395. doi: $10.1016 /$ j.paid.2009.04.008.

Swann, A. C. \& Hollander, E. (2002). Impulsivity and aggression: Diagnostic challenges for the clinician. Illinois: ACCESS Medical Group.

Tantillo, M., Kesick, C. M., Hynd, G. W., \& Dishman, R. K. (2002). The effects of exercise on children with attentiondeficit hyperactivity disorder. Medicine \& Science in Sports \& Exercise, 34(2), 203-212. doi: 10.1097/00005768-20020200000004.

Vasconcelos, A. G., Malloy-Diniz, L., \& Correa, H. (2012). Systematic review of psychometric proprieties of Barratt Impulsiveness Scale Version 11 (BIS-11). Clinical Neuropsychiatry, 9(2), 61-74.

Vaynman, S., \& Gomez-Pinilla, F. (2005). License to run: exercise impacts functional plasticity in the intact and injured central nervous system by using neurotrophins. Neurorehabilitation and Neural Repair, 19(4), 283-295. doi: 10.1177/1545968305280753.

Verret, C., Guay, M. C., Berthiaume, C., Gardiner, P., \& Béliveau, L. (2012). A physical activity program improves behavior and cognitive functions in children with ADHD: An exploratory study. Journal of Attention Disorders, 16(1), 71-80. doi: 10.1177/1087054710379735.

Wan, Y., Zhang, M., Jin, F., \& Cheng, Z. (2016). The Chinese version of the Barrett Impulsiveness Scale-11: Reassessment of its psychometric properties in three adolescent samples. Journal of Psychiatry and Brain Science, 1(3), 1-9. doi: 10.20900/jpbs.20160011.

Weber, W., Vander Stoep, A., McCarty, R. L., Weiss, N. S., Biederman, J., \& McClellan, J. (2008). Hypericum perforatum (St John's wort) for attention-deficit/hyperactivity disorder in children and adolescents: a randomized controlled trial. Jama, 299(22), 2633-2641. doi: 10.1001/jama.299.22.2633.

Weinberg, R. S., \& Gould, D. (2003). Foundations of sport and exercise psychology. Champaign, IL: Human Kinetics.

Weiss, T., Kreitinger, J., Wilde, H., Wiora, C., Steege, M., Dalleck, L., \& Janot, J. (2010). Effect of functional resistance training on muscular fitness outcomes in young adults. Journal of Exercise Science \& Fitness, 8(2), 113-122. doi: 10.1016/S1728-869X(10)60017-2.

Wigal, T. I. M., Greenhill, L., Chuang, S., McGough, J., Vitiello, B., Skrobala, A., Swanson, J., Wigal, S., Abikoff, H., Kollins, S., McCracken, J., Riddle,M., Posner, K., Ghuman, J., Davies, 
M., Thorp, B., \& Stehli, A. (2006). Safety and tolerability of methylphenidate in preschool children with ADHD. Journal of the American Academy of Child \& Adolescent Psychiatry, 45(11), 1294-1303. doi: 10.1097/01.chi.0000235082.63156.27.

Wipfli, B. M., Rethorst, C. D., \& Landers, D. M. (2008). The anxiolytic effects of exercise: a meta-analysis of randomized trials and dose-response analysis. Journal of Sport and Exercise
Psychology, 30(4), 392-410. doi: 10.1123/jsep.30.4.392.

Yao, S., Yang, H., Zhu, X., Auerbach, R. P., Abela, J. R., Pulleyblank, R. W., \& Tong, X. (2007). An examination of the psychometric properties of the Chinese version of the Barratt Impulsiveness Scale, 11th version in a sample of Chinese adolescents. Perceptual and Motor Skills, 104(3), 1169-1182. doi: 10.2466/pms.104.4.1169-1182. 